\title{
Entre o lixo e as esmeraldas: a presença da obra de Efigênia Rolim dentro do Museu Oscar Niemeyer
}

\author{
Larissa Busnardo ${ }^{1}$ \\ André Americano Malinski ${ }^{2}$ \\ Paula Rigo Tramujas ${ }^{3}$
}

Resumo: O que diferencia as esmeraldas do lixo? Diante do brilho espelhado de um papel de bala, Efigênia Rolim (1931) percebeu a oportunidade de transformar algo desprezado em um objetivo de vida. Essa ressignificação do lixo em sua epifania propicia uma necessária mudança de olhar sobre os excessos do cotidiano, habitualmente desprezados por nossa sociedade de consumo. Sendo assim, Efigênia conquista o espaço museológico e o público da Bienal Internacional de Curitiba no Museu Oscar Niemeyer, com sua atuação performática e suas obras construídas do ínfimo, causando estranheza pela estética não convencional e recheando de vida e beleza o que comumente é considerado feio e sem valor.

Palavras-chave: Cultura popular, Ecologia, Efigênia Rolim, Museu de Arte, Performance.

Abstract: What makes the difference between the emeralds from the trash? Facing de shining mirrored of the candy wrapper, Efigênia Rolim (1931) found the opportunity of changing a dismissed thing into her life goal. This trash resignificance in her epiphany allows a necessary change of view of the everyday excesses, usually despised by our consumer society. Thus, Efigênia conquer the museum space and the public of the Curitiba's International Bienial in the Museu Oscar Niemeyer with her pieces made by the lowermost, causing strangeness by the use of unconventional aesthetic, filling with life e beauty what commonly is considered ugly and unvalued.

Keywords: Ecology, Efigênia Rolim, Art Museum, Performance, Popular Culture.

\footnotetext{
${ }^{1}$ Pesquisadora graduada em Licenciatura em Artes Visuais pela FAP/UNESPAR, acadêmica da especialização em História Cultural na UTP. Oficineira do MON em 2012 e 2013.

2 Acadêmico graduando em Licenciatura em Artes Visuais pela EMBAP/UNESPAR, vinculado ao grupo de pesquisa NAVIS. Oficineiro do MON em 2013 e 2014.

3 Professora colaboradora da EMBAP/UNESPAR, Mestre em Comunicação e Linguagens pela UTP.
} 
"Vitrine, joias de ouro, eu virei prum outro lado Descobri o meu tesouro foi no lixo reciclado." Efigênia Rolim

\section{Introdução}

Este artigo foi desenvolvido a partir da experiência de atuação nas oficinas artísticas ministradas no Museu Oscar Niemeyer. Sendo que ali tivemos a oportunidade de realizar algumas propostas práticas relacionadas às obras de Efigênia Rolim que foram expostas no museu durante o evento da Bienal Internacional de Curitiba em 2013. Tal prática nos instigou intensas discussões sobre a artista, suas obras e o funcionamento interno do MON, assim como sobre as atividades desenvolvidas nas oficinas. Enquanto oficineiros da Ação Educativa, tivemos a oportunidade de observar o funcionamento do museu internamente, porém ao mesmo tempo em que obtínhamos a experiência de estar inseridos naquele local talvez conseguíssemos compreender também o contexto visto de fora, pelo fato de não existir um vínculo empregatício com a instituição. Em complemento a isto, estar simultaneamente no ambiente acadêmico e museológico promoveu uma reflexão mais intensa especialmente sobre a obra de Efigênia. Ou seja, o campo de trabalho onde nos encontrávamos logo se transformou em um campo de pesquisa.

Neste sentido, ao observarmos uma interessante relação dos funcionários do MON e do público participante das oficinas com as obras da artista, esta se tornou um mote para uma investigação. No caso, as 
práticas educacionais propostas demonstraram uma mudança na forma de perceber o trabalho de Efigênia, principalmente para aqueles que entraram em contato com a artista pessoalmente. Ao narrarmos nossas percepções sobre as oficinas e sobre os relatos desses indivíduos, nós utilizamos fontes orais - que são pouco objetivas - não observando os fatos diretamente, mas permitindo "rastrear as trajetórias inconscientes das lembranças e associações de lembranças" e permitindo "compreender os diversos significados que indivíduos e grupos sociais conferem às experiências que têm.” (AMADO, 1995, p. 135). Porém, em nossa análise não temos a intenção de criar generalizações, e tampouco apresentamos as reações observadas como as únicas possíveis.

Desta forma, a partir de uma breve abordagem sobre a trajetória de Efigênia Rolim como artista, antes e depois de seu famoso encontro com o papel de bala na Rua XV, pretende-se analisar as principais características das obras de Efigênia, considerando que a artista, na maioria das vezes, se torna a própria obra. Desta forma, propomos uma reflexão sobre os temas observados na obra de Efigênia e nossa prática dentro da Ação Educativa, buscando por fim compreender se, de fato, as performances de Efigênia Rolim e seus objetos construídos de lixo (que são essenciais para os processos criativos e atuação da artista) realmente proporcionaram novas provocações e transformações no encontro com o público de um grande museu. 


\section{Uma personagem da cultura popular?}

A feirinha do Largo da Ordem, um ambiente de comércio de artesanato e de arte popular da cidade de Curitiba, foi o espaço onde Efigênia Rolim desenvolveu sua trajetória artística transformando lixo em histórias entre as barracas domingueiras dos artesãos. Batizada por si mesma como a "artista pé de chinelo", entre outros títulos, Efigênia se estabeleceu como uma das principais personagens folclóricas da cidade, ao lado, por exemplo, do amigo, parceiro profissional e vizinho de barraca, Hélio Leites ${ }^{4}$ (1951).

Para abordar a obra de Efigênia Rolim, é necessário compreender a estreita relação entre o processo de produção de sua obra e o que se classifica como "cultura popular", um conceito que, de acordo com Nuno Saldanha (2008, p. 106), é ambíguo e "quase tão indefinível quanto a própria arte”. Isto significa que, a princípio, não existe uma resposta adequada sobre tal expressão. Procurando uma conceituação, Saldanha apresenta a "arte popular" como aquela desenvolvida fora dos padrões estabelecidos, em termos de conteúdo, tema, instrumento, técnica ou material. Assim, é importante advertir que o termo "cultura popular" se trata de um conceito atrelado a uma distinção de valores, pois sugere um ato cultural menor $\mathrm{e}$ alheio àqueles que seriam favorecidos socialmente como o ideal, ou seja, como a "cultura erudita". Segundo

\footnotetext{
${ }^{4} \mathrm{O}$ paranaense Hélio Leites é poeta, performer e criador do Museu do Botão. Trabalha com objetos como caixinhas de fósforo, botões, rolhas, latas, madeira e restos de material entalhado que, por suas mãos, transformam-se em personagens que contam histórias, prendendo a atenção de crianças e adultos. (Fonte: Dia a Dia Educação).
} 
Pierre Bourdieu (2003), a erudição é historicamente construída, acatando a determinadas leis de construção e a um gosto estético arbitrariamente estabelecido e imposto. Ou seja, para Bourdieu a legitimação de determinadas manifestações culturais em oposição a outras se deve, essencialmente, a uma representação social dicotômica entre "bárbaros e civilizados", entre "sagrados e profanos".

Se tal é a função da cultura e se o amor pela arte é exatamente a marca da eleição que, à semelhança de uma barreira invisível e intransponível, estabelece a separação entre aqueles que são tocados pela graça e aqueles que não a receberam, compreende-se que, através dos mais insignificantes detalhes de sua morfologia e de sua organização, os museus denunciem sua verdadeira função, que consiste em fortalecer o sentimento, em uns, da filiação, e, nos outros, da exclusão. (BOURDIEU, 2003, p. 168)

Deste modo, no espaço museológico, se dá o reconhecimento de uma única representação cultural como erudita, enquanto outra é determinada como popular, não é uma distinção inofensiva, mas sim impregnada de julgamentos de valor, num sistema estanque que não leva em consideração a influência recíproca entre ambas.

No entanto, se tomarmos a devida precaução quanto a esta distinção cultural, é possível identificar algumas particularidades comuns entre as obras dos artistas considerados "populares". Ou seja, observando-a como uma forma heterogênea de arte, que se realiza com considerável liberdade de escolha e de experimentação, completamente solta dos limites impostos sobre materiais e temáticas e que, via de regra, 
é exposta fora das instituições formais. Talvez em decorrência de tal liberdade a poética "popular" tenha uma ligação intensa com a linguagem narrativa e suas particularidades: sua ludicidade, a ingenuidade e a aspiração pelo que é bizarro, a sabedoria da transmissão oral e o folclore (SALDANHA, 2008).

Portanto, é possível descrever a produção de Efigênia Rolim como uma forma de manifestação mais aproximada da "cultura popular", através de algumas características marcantes, principalmente em suas performances, pois quando narra suas histórias ela se torna, por si mesma, a obra de arte. Sobre as fábulas de Efigênia, por exemplo, nota-se que elas contêm sempre algum tipo de sabedoria simbólica típica da figura do narrador, que, parafraseando Walter Benjamin, pode aparecer com "um ensinamento moral, seja numa sugestão prática, seja num provérbio ou numa norma de vida" (1994, p. 200). Conforme pode ser observado na “A história do peixe voador", onde ela usa o personagem de ambiente aquático para dar um mergulho em si mesma e tratar sobre suas próprias crenças e questões morais:

O peixinho deu um salto e foi embora. Eu me acordei e chorei. Moral da história: Só ficou a memória. Onde está o peixinho? Onde o peixinho mora? Na emoção, no fundo do coração. (ROLIM apud PINHEIRO, 2012, p. 6)

Além da narrativa, outra principal característica popular em Efigênia Rolim é o uso de materiais não convencionais, como o lixo. Essa particularidade demonstra a afinidade de sua atividade artística com o 
artesanato - o próprio Walter Benjamin (1994, p. 205) descreve o ato da narrativa como uma artesã - e é encontrada também, na obra de outros "artistas populares".

Se o reaproveitamento, por parte dos artistas populares, de materiais descartados os mais diversos muitas vezes é interpretado como fruto da falta, da carência e da pobreza, na arte erudita desde os dadaístas é possível perceber que a assimilação de materiais preexistentes, não convencionais, materiais orgânicos, inorgânicos e industriais, foi considerada proposta consciente de ruptura com a visão institucional da arte (WALDECK, 2007, p. 7)

Nesse sentido, costuma-se comparar o trabalho de Efigênia Rolim com o de Arthur Bispo do Rosário5 (1911-1989) inserir rodapé dizendo de quem se trata em uma ou duas linhas. Ranchinho ${ }^{6}(1923-$ 2003) e o próprio Hélio Leites (PINHEIRO, 2012, p. 67-69). Como eles, Efigênia extrapola os conceitos de artesanato e de arte popular, construindo trabalhos que estão além dessas classificações, e que se conservam bastante à margem do que se poderia considerar uma produção artística popular ou mesmo erudita. Ela se tornou as duas coisas e, ao mesmo tempo, nenhuma delas. Portanto, antes de realizarmos uma análise mais direta sobre suas obras, buscaremos compreender quem é

\footnotetext{
${ }^{5}$ Sergipano, Arthur Bispo era descendente de escravos africanos e foi marinheiro no Rio de Janeiro. Foi diagnosticado como esquizofrênico e internado na Colônia Juliano Moreira. Elaborava objetos profundamente requintados utilizando materiais retirados do lixo e da sucata além de retirar fios de outras roupas para bordar. (PINHEIRO, 2012, p. 67).

${ }^{6}$ Ranchinho (Sebastião Theodoro Paulino da Silva) viveu em Assis no interior de São Paulo, foi um pintor que retratou a cultura caipira. (PINHEIRO, 2012, p. 68).
} 
Efigênia Rolim e como ela se tornou a tão simples e sofisticada "rainha do papel de bala".

\section{A cortadora de cana que virou rainha}

Nas terras mineiras do Abre Campo, finalzinho de 1931, nasceu uma menina magrinha, desnutrida mesmo, numa família que vivia da colheita do café. A menina só sobreviveu pelo empenho da avó e da mãe, que the alimentavam com leite por um conta-gotas. Deram-lhe o nome de Efigênia. Ela cresceu na roça, brincando com os retalhos de pano da avó. Como seu pai considerava brincadeiras com bonecas uma perda de tempo - ele achava melhor que seus filhos se ocupassem de outros assuntos - e Efigênia precisou se valer de sua imaginação. Quando entrevistada por Dinah Pinheiro, ela contou que seu pai era um homem rígido: "meu pai era muito brabo, não me deixava ir à escola, regulava os namoros" (PINHEIRO, 2012, p. 39). Assim foi que Efigênia virou moça e então, aos 19 anos, se casou com Francisco, com quem foi morar em Jatimboca, onde ambos trabalharam como cortadores de cana e tiveram sete dos nove filhos. Já na década de 60, o irmão de Francisco convidou-os para se instalar com ele em uma fazenda na região de Londrina, onde chegaram durante um inverno rigorosíssimo que destruiu toda a lavoura. Para resistir à falta de dinheiro, ao frio e à saúde fraca de Francisco, Efigênia trabalhou como doméstica e boia fria, e não teve acanhamento de pedir por ajuda. Finalmente, cansados daquela vida, eles decidiram mudar-se para Curitiba na década de 1970, procurando por oportunidades melhores. 
Na capital, Efigênia e Francisco precisaram viver de caridade, e se alojaram de favor com uma religiosa. Rever o português: Mas a ajuda sempre lhes aparecia: uma vez, Efigênia teve uma conversa com uma elegante senhora cuja filha vivia na Europa e destinara um dinheiro para doação. Tocada pela história de Efigênia, a senhora the doou aquela quantia. No entanto, outras dificuldades ainda surgiriam na trajetória de Efigênia, pois o marido, Francisco, acabou falecendo em decorrência de sua doença:

O homem que eu mais amei Nove filhos ele me deu

Quando menos esperei

Nos meus braços ele morreu. (ROLIM apud PINHEIRO, 2012, p. 30)

Foi ainda obrigada a desocupar sua nova casa e sofreu com os danos de uma cirurgia malsucedida de catarata. No entanto, segundo Efigênia, apesar de ter precisado por toda vida "matar um leão por dia", ela conseguiu não apenas manter sua dignidade, mas também ajudar a outras pessoas, voltando-se para a causa social, atendendo crianças abandonadas e doentes.

Num dia difícil como qualquer outro, quando Efigênia andava pelo calçadão da rua XV de Novembro, cheia de preocupações na cabeça, ela encontrou algo que transformaria sua vida. Não se tratava de nenhuma senhora caridosa, nem era nada muito misterioso. Foi um simples papel de bala brilhante jogado no chão. Um objeto banal, mas responsável por despertar em Efigênia a artista que permanecera até então adormecida. 


\section{A natureza da "Rainha do Papel de Bala"}

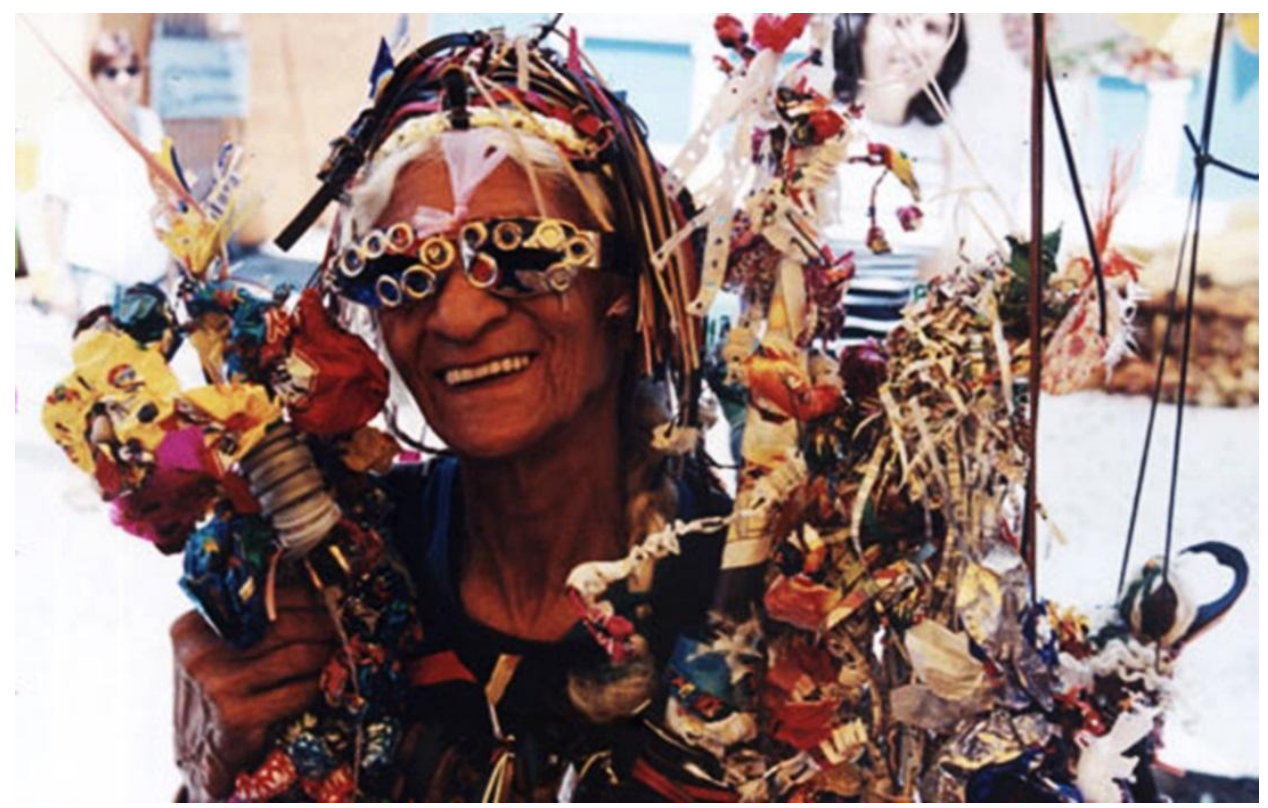

Figura 1: Efigênia na Feirinha do Largo da Ordem.

Fonte: PINHEIRO, 2012, p.86.

Quando paramentada, a figura de Efigênia Rolim se destaca entre os passantes anônimos nas ruas de Curitiba, notadamente por sua indumentária inteiramente feita de lixo. Seus vestidos, calçados e acessórios têm um aspecto chamativo pelo colorido vibrante das embalagens plásticas e pelas particularidades evidenciadas de cada rótulo, suas logomarcas, seus formatos, e a sujeira urbana que foi incorporada ao objeto. Por vezes Efigênia também leva consigo bonecos construídos com os mais diversos materiais que encontra na rua, que são criteriosamente escolhidos e reaproveitados, sem camuflar o estado em que foram encontrados. Na fotografia anterior, por exemplo, é possível identificar estas características. 
Pode-se dizer, portanto, que Efigênia carrega todos os dias em sua própria figura a história de como se descobriu uma artista. É continuamente rememorado o episódio de sua inspiração inicial, que surgiu de uma epifania após o encontro com um precioso papel de bala:

O mítico encontro de Efigênia com o papel de bala, em 1991, na Rua XV de Novembro, ao lado do Bondinho, foi o acontecimento mágico e emblemático que mudou os rumos da sua vida. 'Eu ia andando despreocupada pela rua quando vi algo brilhando muito. Tinha a cor verde. Logo pensei que seria esmeralda, uma pedra preciosa, de muito valor. Quando toquei o objeto e percebi que se tratava de papel de bala, alguma coisa mudou dentro de mim'. (PINHEIRO, 2012, p. 59)

O que inicialmente pareceu um simples equívoco, logo foi substituído pela inventividade bem humorada de Efigênia, que tirou daquela experiência improvável uma nova incumbência, a de oferecer vida nova ao que foi impiedosamente descartado. Segundo a artista, foi o próprio papel de bala quem lhe pediu: "estamos jogados no chão. Ninguém nos dá valor. Somos lixo. Para valer mais do que pérola nós precisamos de vida e é você que vai tirar a gente do lixo e fazer da gente uma arte" (EFIGÊNIA apud WALDECK, 2007, p. 12). A história se resolveria da seguinte forma:

Mais à frente, encontrou um pé de chinelo e teve a ideia de unir os dois "achados". Cuidadosamente, colocou o papel da bala no centro desse chinelo, junto com um palitinho, e amarrou tudo com um fio tirado de sua própria roupa. Neste dia, nasceu "Efigênia, uma artista da sucata, uma pé de chinelo". (DANTAS 
Foi, portanto, a partir de uma transformação particular da forma de compreender a potencialidade do lixo como material poético, carregado de significados, que Efigênia abraçou sua missão artística. Sobre a decisão insólita da artista ao resolver o caso do papel de bala, Michele Czaikoski comentou:

Efigênia não compreendia como era possível dar vida a um papel de bala, até que ele (o papel) explicou, numa belíssima metáfora, que nos deixa perceber o quanto a artista considera sua obra uma missão: dar vida ao papel de bala é tirar do chão aquilo que foi amado enquanto tinha recheio, mas foi posto de lado, esquecido, pisoteado quando o recheio, a essência se foi. 'É levantar os caídos', conta-nos Efigênia, 'é cuidar do que é frágil'. (CZAIKOSKI apud PINHEIRO, 2012, p. 59)

Levando em consideração a trajetória de vida intrincada de Efigênia Rolim antes de sua epifania, parece que a tentativa de "levantar os caídos" através do lixo seria, na realidade, um reflexo da necessidade de transformação da sua própria vida, ou seja, poderia significar a possibilidade de que ela própria "se levantasse". Ela provavelmente tenha se visto refletida naquele espelhado papel de bala, e assim, ao decidir resgatar este esquecido resíduo urbano, estabeleceu um resgate de sua própria vida - o que torna compreensível que este evento mereça ser relatado por ela incansavelmente. Nesse sentido, vale apontar que Efigênia relaciona sua vida e sua ficção nas suas obras. Fazendo uma comparação entre o recheio de um papel de bala e a sua própria essência, 
ela comentou: "trabalhar com o papel de bala é trabalhar com a minha própria vida. Eu jamais posso perder o meu recheio. $\mathrm{O}$ dia que eu perder o recheio, eu... puf!" (O FILME DA RAINHA apud KASPER, 2014, p. $335)$.

Através do improviso ao vivo, Efigênia Rolim construiu sua poética, junto a seu amigo Hélio Leites. Assim como Hélio, Efigênia exercita em suas narrativas a empatia com o público: basta começar a conversar com a artista que ela logo encarna uma personagem e começa a contar histórias, a recitar e improvisar novas e antigas poesias. Quem a conhece sabe que ela quase nunca conta a mesma história, e quando o faz, inventa uma versão diferente. Ao mesmo tempo em que inventa e conta suas fábulas, ela canta, desenha, cria novos instrumentos musicais e, principalmente, utiliza seu próprio corpo, sua indumentária e seus bonecos como objetos performáticos. Além disso, cada boneco de que ela dispõe é um personagem com identidade própria e possui um nome, uma história e uma função dentro da performance da artista, de acordo com Kátia Kasper:

Aliada a eles, [Efigênia] apresenta uma performance especial, pois cada boneco tem uma história própria. $\mathrm{Na}$ construção do boneco vemos, muitas vezes, emaranhar-se fragmentos da história de vida da própria Efigênia. Como se o movimento de criação dos bonecos envolvesse, também, um reinventar-se de Efigênia na construção dessas narrativas. [...] os bonecos e Efigênia nos contam, falam-nos de várias coisas: desde como eles foram criados, suas histórias, e o que têm a trazer para nosso mundo. Ou como desformá-lo. (KASPER, 2014, p. 341) 
Enquanto interage com alguém ou constrói seus objetos, portanto, Efigênia transforma toda sua ação em um ato poético. Quando Marshall McLuhan escreveu sobre "o poder da voz em moldar o ar e o espaço em formas verbais" (2000, p. 98) ao discorrer sobre a palavra falada, ele talvez estivesse se referindo à mesma sensação que temos ao nos encontrarmos com Efigênia Rolim: o sentimento da narrativa como uma obra plástica a ser moldada, trabalhada, transformada pela mão criativa - ou talvez pela voz criativa. Os limites entre as linguagens começam a perder-se, e essa atuação interdisciplinar de artistas como a Efigênia faz pensar, enfim, na natureza de sua obra (afinal, o que ela faz é literatura, música, artes visuais ou artes cênicas?). De acordo com Tania Alice (2014), a performance é caracterizada por uma mescla de diversas linguagens: se trata de um pouco de tudo, de uma "indisciplina" artística. Sobre o significado do termo "performance", a autora comenta:

Em termos de etimologia, quando falamos de 'performance', podemos nos referir à definição que o linguista inglês Austin propõe: todo ato de fala contém um poder de transformação inerente a ele mesmo. Cada fala realiza uma ação ao mesmo tempo que é proferida: une, afeta, legitima, impede, afasta... Por modificar o contexto em que é proferida, a fala performativa se constitui como um poder de ação e de transformação. É nesse sentido que podemos entender a performance: como uma linguagem que não constitui apenas uma representação de determinada situação ou contexto, mas que, realizando e efetuando-se modifica o presente, influi ativamente nele, propondo transformações nos modelos vigentes, tornando visível o invisível, e palpável o despercebido 
Deste modo, levando em consideração o caráter interdisciplinar e relacional da performance, nota-se que a obra de Efigênia Rolim pode ser sistematizada através de seu caráter performativo. Isto se dá principalmente pelo fato dela invadir os espaços mais diversificados, na maioria das vezes utilizando-se da rua, além de sua própria figura, como objeto de sua proposta artística. Por fim, levando em consideração o caráter da linguagem performática ao propor uma transformação da realidade, como observado por Alice, compreende-se que a própria motivação de Efigênia sobre sua prática artística relaciona-se ao princípio de engajamento da performance. O ideal proposto pela artista, no caso, é a busca dos ideais de defesa da ecologia, pois ao utilizar o lixo como matéria prima de sua obra ela também critica o desperdício e a acumulação da sociedade contemporânea, em sintonia com outros performers que se preocupam com esta causa, como abordado por Tania Alice:

A performance como prática espiritual, existencial, como fusão de arte e vida, intensificação de afetos e das relações. Como abraço planetário, ecologia social, ambiental, da subjetividade e como poder de transformação potente e potencializador. Como imaginação liberada, desterritorialização de afetos, invenção do cotidiano, longe de imaginários padronizados. A performance como reterritorialização na terra fértil dos possíveis, como resposta a urgência de cuidar de si, do outro e do planeta, como estética emergente e urgente de um mundo globalizado. (ALICE, 2014, p. 45) 
Sobre a relação entre a performance e a ecologia, portanto, aponta-se que existem muitos performers preocupados com o tema da subjetividade dessa sociedade que evoca o desperdício, a acumulação e o consumo, utilizando-se principalmente do reaproveitamento de despojos. Sobre esta questão, Guacira Waldeck (2007, p. 18) interpreta que o papel da arte seria o de modificar o significado desses objetos descartáveis que são consumidos e rejeitados, reinvestindo-os de novos significados e transformando-os de "despojos" em "matéria prima". Nesse sentido, o tema da ecologia se apresenta na obra de Efigênia Rolim, o que torna, portanto, evidente a relação de sua obra com o contexto contemporâneo da arte.

No entanto, é importante pontuar que apesar da obra de Efigênia parecer se enquadrar, em determinados aspectos, a estilos e conceitos da arte, sua produção não é limitada a este ou aquele formato de arte. De acordo com Waldeck (2007, p. 15), é questionável convocar terminologias eruditas generalizantes para tratar de uma artista para quem esses movimentos "não fazem o menor sentido".

$\mathrm{O}$ que a artista tenta transmitir jamais é apreendido em sua totalidade pelo expectador (ou o indivíduo que possui uma expectativa). $\mathrm{O}$ entendimento da obra passa por um processo de ressignificação ${ }^{7}$ que

\footnotetext{
${ }^{7}$ Qualquer objeto possui uma função primordial. Quando este significado funcional é subvertido, existe um processo de ressignificação. Como exemplo clássico pode-se citar Marcel Duchamp que, ao recontextualizar a latrina, pondo-a em uma exposição de arte e chamando-a de "A fonte" descontruiu o conceito de arte e de latrina ao mesmo tempo. No caso da Efigênia, o significado recriado pode surgir sob três aspectos: um deles é formado pelas partes de que a vestimenta é composta (o "lixo" agregado de modo a
} 
pode ser embasado nas teorias de análise semiótica discutidas por Charles Peirce, que de acordo com Santaella (2002) analisa o teor imagético do discurso apresentando categorias formais e universais em todos os fenômenos que se apresentam à percepção e à mente: a primeiridade, secundidade e terceiridade. Em relação às obras de Efigênia, a primeiridade se daria pela identificação dos elementos que compõem sua indumentária, ou seja, o "lixo" coletado pela artista (papeis de bala, garrafas pet, copos plásticos, etc). A secundidade se colocaria pelo conjunto do traje propriamente dito, formando uma espécie de vestido. A terceiridade ficaria a encargo do próprio expectador; que observa e espera, dentro de um contexto pré-estabelecido, definir e julgar a obra de arte. Ou seja, o processo de terceiridade é peculiar de cada indivíduo, a partir de suas referências e de seu repertório para interpretar a obra a seu modo. Tanto o criador quanto o espectador pode se apropriar do objeto enquanto ressignificação, pois cada um vê o mundo à sua maneira. A arte pode servir como este canal de atribuição de significados, num processo contínuo de ir e vir entre o emissor e o receptor (criador e expectador). Quem sabe, portanto, Efigênia Rolim, enquanto uma artista "pé-dechinelo", não precise se enquadrar, nem ser explicada, mas sim experimentada individualmente, pois, como sugere Walter Benjamin (1994, p. 203), "metade da arte narrativa está em evitar explicações".

formar uma peça de vestuário), outro aspecto é o do conjunto criado (a vestimenta em si), finalizando com a ressignificação por parte do expectador. 


\section{Da feirinha ao espaço museológico: A Efigênia e o MON}

Entre outros espaços escolhidos para compor a programação da Bienal Internacional de Curitiba $^{8}$ do ano de 2013, foram utilizadas algumas salas do Museu Oscar Niemeyer (MON), onde ficaram expostas obras de 36 artistas contemporâneos brasileiros escalados especialmente para o evento. Dentre estes artistas estava Efigênia Rolim, com uma sala separada especialmente para ela. Em meio a seus objetos encontravam-se alguns de seus trajes, bonecas e bichos com alças, todos feitos de lixo coletado pela artista. Por essa particularidade, ainda no período de preparação e montagem das exposições os trabalhos da Efigênia Rolim se tornaram assunto recorrente e controverso nos bastidores do museu. $\mathrm{O}$ estranhamento não aconteceu apenas pelo uso do lixo como matéria prima ou por sua estética incomum, mas principalmente pelo equívoco da distinção entre os lugares da arte erudita e popular. Pois, à primeira vista, encontrar obras como as de Efigênia Rolim dentro de um museu - uma instituição que Pierre Bourdieu (2003) descreveu como um espaço de erudição - causou um estranhamento geral. Aos observadores desavisados, parecia não caber a uma artista vinda da feira um espaço tão especial dentro de um evento do porte da Bienal Internacional de Curitiba. Historicamente, de acordo com Rento Almeida (apud Waldeck, 2007, p. 16), a feira é percebida, como o espaço da cultura popular e distinto do espaço solene das galerias. Não obstante, Efigênia Rolim, a mesma artista

\footnotetext{
${ }^{8}$ A Bienal Internacional de Curitiba era anteriormente nomeada como Bienal Ventosul, e completava 20 anos em 2013.
} 
que participou da "Feira do Poeta" em Curitiba - onde publicou livros com seus desenhos simples e suas poesias gramaticalmente despreocupadas (PINHEIRO, 2012, p. 45) - começou a adentrar a galeria. Na realidade, antes da Bienal, ela já havia de fato participado de outras exposições em museus, como por exemplo, no próprio MON na mostra "Bispo do Rosário +3", uma proposta do curador Ricardo Aquino, com obras de José Rufino e do Bispo do Rosário.

Independente dos debates controversos sobre as obras de Efigênia Rolim dentro do museu, a artista foi ganhando mais e mais importância dento da Bienal, chegando a ser escolhida pela equipe de organizadores e pelo Instituto Arte na Escola para compor o material educativo do evento. Efigênia foi, portanto, uma entre os dez artistas abordados nesse material de apoio didático, que é voltado aos professores, e apresenta algumas abordagens de mediação em arte relacionando a obra de Efigênia a temas recorrentes da arte contemporânea. Isso, de certa forma, demonstra que os organizadores do evento perceberam no trabalho da artista um potencial educativo pelo seu caráter multifacetado.

Além de figurar no material educativo, Efigênia Rolim também foi escolhida para participar da abertura oficial da Bienal com uma performance no MON. É provável que os organizadores do evento tenham percebido a recepção positiva do público curitibano ao interagir com a artista. Pois, durante o evento de abertura, a figura performática da "Rainha do Papel de Bala" foi uma atração bem recebida. O fenômeno descrito por Kátia Kasper, que descreveu a potência das narrativas de 
Efigênia ao envolver, igualmente, os adultos e as crianças, que as escutavam atentamente $(2014$, p. 333$)$ foi percebido logo que a artista apareceu. O público não apenas acompanhava sua atuação, mas também a fotografava e solicitava sua participação posando ao lado deles em seus registros fotográficos. A partir desta experiência performática, não seria mais possível para essas pessoas separar a obra de Efigênia de suas histórias, nem de sua figura eloquente. Ou seja, não era apenas o fato da artista estar vestida com roupas feitas de lixo, de maneira similar aos objetos expostos, que motivava as pessoas a fotografá-la ou tê-la posando ao lado para suas fotos. Acreditamos que isso aconteceu especialmente pelo fato de que, naquele momento, o encontro com a artista se transformava na própria obra. E desta forma o assédio do público com a artista se repetiu sempre que ela apareceu paramentada pelo museu, com sua "arte para vestir". 


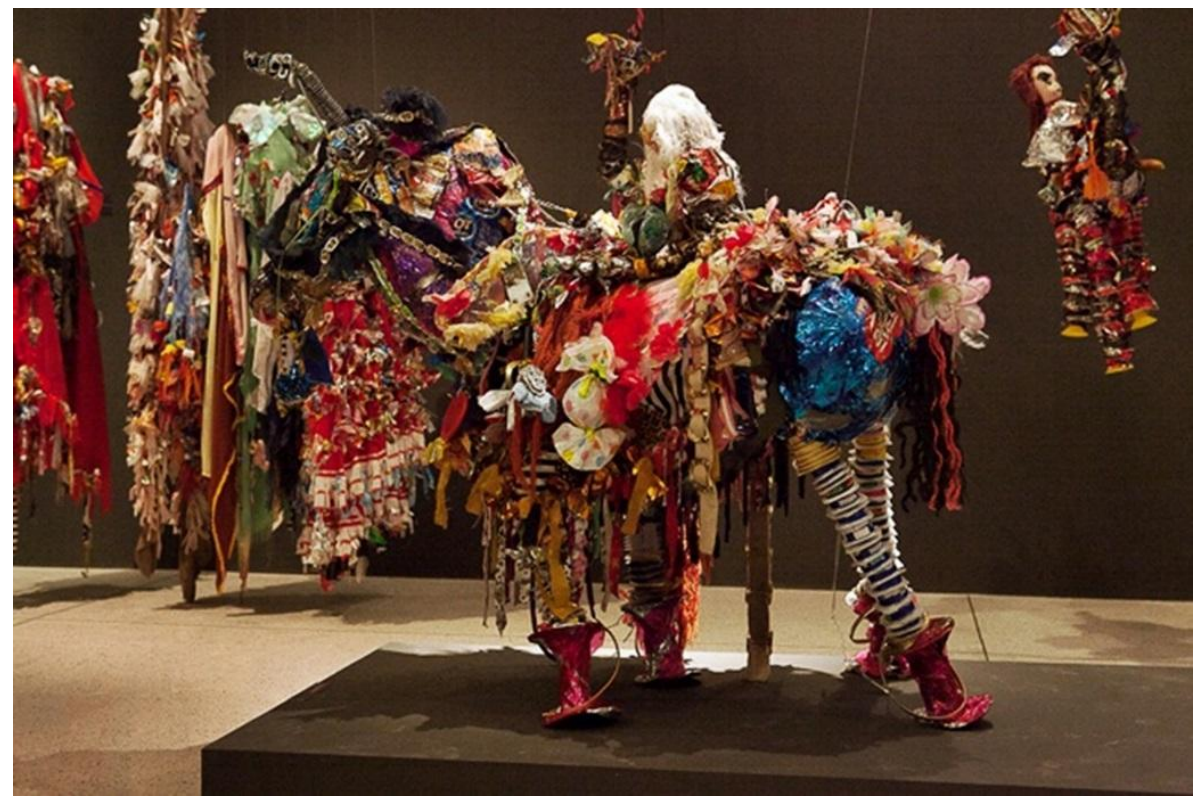

Figura 2: Objetos de Efigênia Rolim na sala separada para a artista durante a Bienal Internacional de Curitiba. Foto de Claiton Biaggi. Fonte: Bienal Internacional de Curitiba, 2013.

$\mathrm{Na}$ fotografia acima vemos, em primeiro plano, um grande cavalo construído de embalagens diversas, enquanto em segundo plano estão penduradas as girafas que Efigênia costuma carregar consigo em suas performances. A girafa mais conhecida é a "Tibúrcia" que de acordo com Pinheiro (2012) serve de amuleto para a artista. Dentro dos conceitos de primeiridade, secundidade e terceiridade a relação sígnica é similar à da indumentária de Efigênia. A recontextualização ocorre em relação ao local onde estas girafas estavam situadas, o Museu Oscar Niemeyer, pois estas obras ficaram expostas como objetos de arte, não como peças de vestir. Suas similitudes podem ser a utilização de materiais descartados que se transformam em outra coisa: uma roupa ou um objeto de arte. 
Somando a receptividade do público e os vários destaques que seus trabalhos ganharam gradativamente dentro do museu, Efigênia Rolim acabou se tornando a protagonista entre os artistas da Bienal Internacional de Curitiba que estavam expostos no MON naquele período. Isso talvez aconteceu devido às obras dela criarem uma aproximação entre arte e vida enquanto os artistas contemporâneos, via de regra, parecem criar afastamentos. Dessa forma, logo depois da abertura da Bienal, Efigênia conquistou também os funcionários do museu, e a equipe do setor educativo, recebendo um convite para ser homenageada como "Artista do mês", durante a programação do "Domingo+Arte". Ou seja, além de ganhar um espaço destacado dentro da própria Bienal, Efigênia também teve seus trabalhos exibidos no espaço expositivo localizado em frente à oficina de arte do museu. O que vem a colaborar com as atividades referentes à artista abordadas dentro das oficinas de arte.

\section{Sobre transformar lixo em esmeralda}

A experiência através das observações de relatos do público sobre a poética de Efigênia e através da prática educativa se deu dentro das oficinas do MON. Em nosso campo de atuação, percebemos que as questões sociais da obra da artista chamavam muita atenção e eram cada

\footnotetext{
${ }^{9}$ Anteriormente denominado "Domingo social", o "Domingo +Arte" se trata de um evento mensal que ocorre durante os primeiros domingos de todos os meses do ano, onde além de oferecer entrada gratuita e atrações de outras manifestações artísticas, o MON oferece também oficinas de arte ministradas por um artista do acervo, homenageado pelo setor educativo.
} 
vez mais relevantes e essenciais para a vida cotidiana dos participantes. Nesse sentido, a própria Efigênia demonstra que sua obra oferece esta faceta didática ao dedicar-se, ela mesma, à educação ${ }^{10}$. Efigênia Rolim costuma frequentar escolas, às vezes acompanhada de seu amigo Hélio Leites, realizando um trabalho que é claramente mais social do que estético, ao levar às crianças o processo de ressignificação dos materiais descartados de que ela tanto se utiliza em suas obras.

O setor da Ação Educativa dentro do Museu Oscar Niemeyer desempenha a função de atender a grupos de visitantes previamente agendados, oferecendo-lhes mediações e oficinas sobre as exposições vigentes. Os grupos agendados são em sua grande maioria compostos por alunos da educação infantil, ensino fundamental e médio de escolas públicas e privadas, sendo estes de Curitiba e da região metropolitana. Não obstante, são atendidas também organizações não governamentais, universidades e outras instituições, vindas não apenas de Curitiba, mas de outras cidades do Paraná e outras regiões do Brasil. A oficina do setor educativo está localizada no subsolo do museu e é composta de uma área expositiva, para o artista homenageado durante o evento "Domingo +Arte”. Ela também possui um espaço para a aplicação de práticas artísticas. Três oficineiros têm a função de aplicar as propostas e desenvolvê-las junto à Ação Educativa.

As propostas artísticas aplicadas na oficina do MON são voltadas especialmente para as exposições vigentes, ou seja, cada

\footnotetext{
${ }^{10}$ O vídeo "Conheça Efigênia, a rainha do papel”, do Canal Futura, mostra esta relação de Efigênia Rolim com a educação e com as questões sociais.
} 
exposição é trabalhada pelos oficineiros com uma proposta diversa. Frente à necessidade de se escolher um tema para desenvolver uma atividade prática sobre a Bienal de Curitiba, foi imediatamente cogitado o nome de Efigênia Rolim. Entre as obras expostas que foram cogitadas como tema para uma proposta artística, encontravam-se alguns de seus trajes, compreendendo vestidos, sapatos, chapéus, entre outros objetos utilizados pela artista em suas performances. Observando estes elementos, foi sugerido o desenvolvimento de chapéus feitos com material reciclado como atividade prática para grupos agendados compostos de crianças com aproximadamente 4 a 8 anos de idade. Por apresentar uma temática voltada para a ecologia e a narrativa, a obra de Efigênia se mostrou adequada para se trabalhar com esta faixa etária, por sua faceta lúdica e mesmo pedagógica, mostrando-se mais acessível. Pode-se dizer que o objetivo principal desta proposta fosse deixar semeadas algumas ideias para que, durante a vida, essas crianças pudessem repensar criticamente seu próprio cotidiano ou mesmo a prática artística.

Desta forma, a atividade relativa à Bienal que foi proposta e este público consistia na elaboração de um chapéu, inspirado no acessório utilizado por Efigênia, sobre o qual seriam agregados, através de assemblagem, os materiais diversos coletados pelos oficineiros. Foi adotado um modelo bastante simples e popular de chapéu, construído por meio de dobraduras, sendo este feito a partir da reutilização de materiais impressos sobressalentes, decorrentes de antigas exposições do museu. Este, então, serviu de base para os visitantes acrescentarem os fragmentos 
de "lixo" disponibilizados sobre as mesas, que consistiam em recortes de embalagens e papéis de bala coletados por funcionários do MON.

Durante a aplicação da proposta, buscava-se interagir ludicamente com as crianças, enfatizando o sentido ecológico da obra de Efigênia, através de perguntas como "Quem aqui joga papel de bala no chão?", seguida da resposta "Eu não!", ou do gesto de um ou outro distraído, que levantava e abaixava rapidamente a mão. Em seguida, se perguntava: "Quem aqui recolhe papel de bala do chão?", momento em que normalmente as crianças ficavam em silêncio, estranhando a pergunta que lhes parece insólita, pois esta atitude não é hábito comum entre as pessoas. Estas questões nos ofereciam a oportunidade de lembrar que Efigênia de fato recolhe lixo das ruas para construir suas obras de arte. A partir deste dado, lembrava-se o mítico encontro da artista com o papel de bala na Rua XV, gesto que promoveu o seu desabrochar artístico. Por fim, enfatizava-se a questão performática e narrativa da obra de Efigênia, apontando que ela utilizava os objetos que construía "para se tornar outra pessoa e contar histórias". Na fotografia, observamos o momento em que André Malinski coloca seu próprio chapéu referente à oficina e começa a inventar um personagem com a ajuda das crianças. 


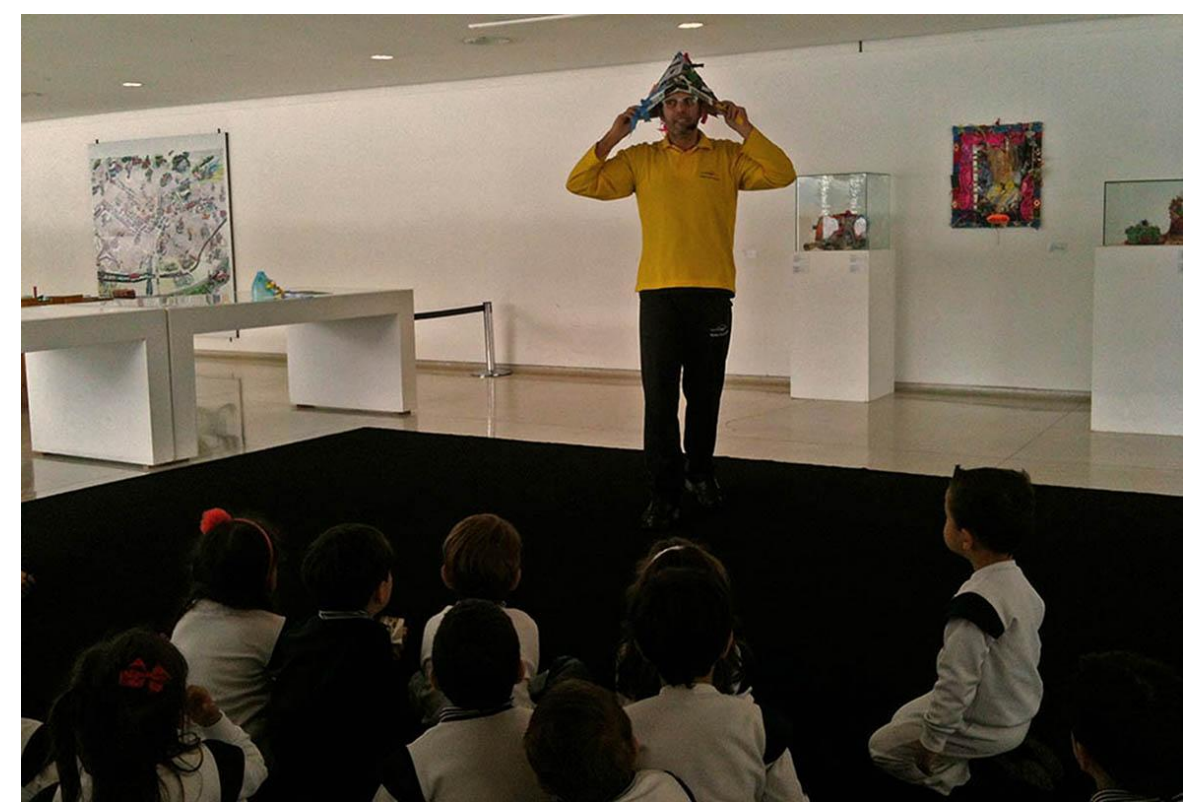

Figura 3: Abordagem inicial da proposta inspirada nos chapéus de Efigênia, no MON. Fonte: Acervo de André Malinski.

As crianças acolheram bem a atividade prática proposta. Embora ela fosse inicialmente pensada para atender às crianças menores, chegou a ser aplicada, de maneira surpreendentemente satisfatória, para adolescentes e também algumas turmas de adultos de diversas idades.

A aplicação desta prática foi gradualmente aprimorada. Percebeu-se, por exemplo, que a proposta corria o risco de se resumir a uma reprodução mecânica. Então, foram enfatizados aspectos como: as intenções da artista com suas proposições e o valor agregado ao lixo quando reutilizado, recheado de histórias e transformado em arte.

A intenção era instigar novas experiências narrativas, ampliar o repertório dos participantes para além do que estavam habituados. Nesse sentido, é interessante lembrar da referência militar reproduzida pelas 
crianças com relação ao modelo de chapéu de dobraduras, pois alguns grupos, na faixa dos cinco anos de idade, costumavam cantar o refrão popular "marcha soldado cabeça de papel" ao formar fila para se locomover dentro do museu. Este comportamento revela a cultura da disciplina que foi "herdada" pelas escolas muito antes da ditadura, uma memória que é "vivida por tabela" 11 " (POLLAK, 1992, p. 201) pelas crianças de hoje.

A ênfase era principalmente na ação performática da artista que englobava a indumentária, as narrativas, o gestual. Efigênia faz objetos artísticos para vestir, com os quais se torna também uma personagem, misturando-se com suas criações. Assim, ao fim da oficina, todos os participantes eram convidados a colocar a indumentária que produziram e continuar a visita noutros espaços expositivos do MON, passando, com este gesto, de simples observadores a personagens que também poderiam ser observados dentro do espaço expositivo.

Posteriormente, durante o "Domingo + Arte", a própria Efigênia Rolim se fez presente nas oficinas, propondo a construção de apitos com mangueiras ${ }^{12}$ (Fig. 4), e depois propondo ainda a montagem de anjos com

\footnotetext{
11 "São acontecimentos dos quais a pessoa nem sempre participou mas que, no imaginário, tomaram tamanho relevo que, no fim das contas, é quase impossível que ela consiga saber se participou ou não. Se formos mais longe, a esses acontecimentos vividos por tabela vêm se juntar todos os eventos que não se situam dentro do espaçotempo de uma pessoa ou de um grupo. É perfeitamente possível que, por meio da socialização política, ou da socialização histórica, ocorra um fenômeno de projeção ou de identificação com determinado passado, tão forte que podemos falar numa memória quase que herdada." (POLLAK, 1992, p. 201)

${ }^{12}$ Proposta realizada no dia 06/10/2013.
} 
sacolas plásticas ${ }^{13}$. A artista chegou inclusive a posar para uma foto portando o chapéu confeccionado pelos oficineiros, o que reforça o quanto ela aprovou a proposta educativa que vinha sendo aplicada com os visitantes agendados (Fig. 5).

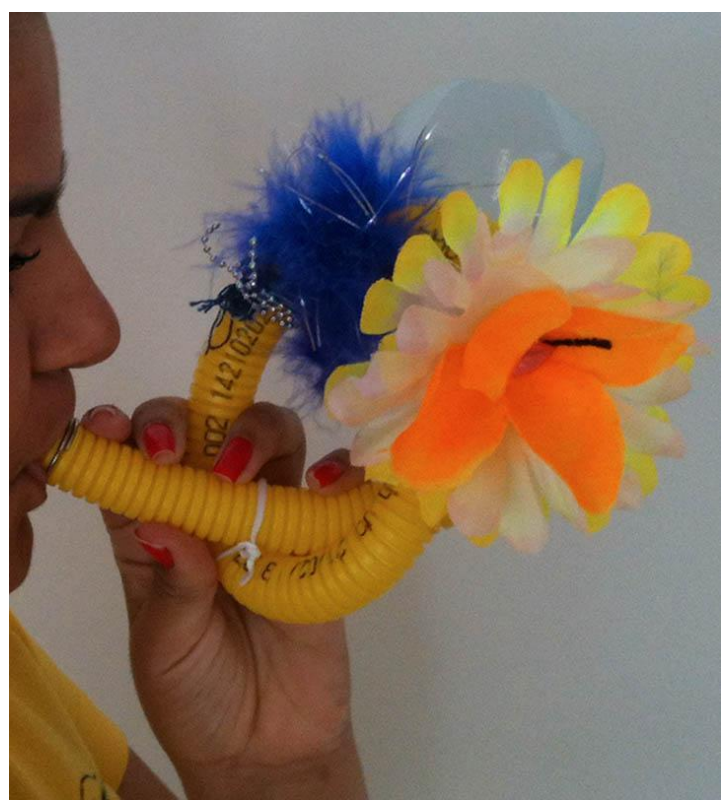

Figura 4: Apito construído durante a oficina do "Domingo + Arte". Fonte: Acervo de André Malinski

${ }^{13}$ Proposta realizada no dia 03/11/2013. 


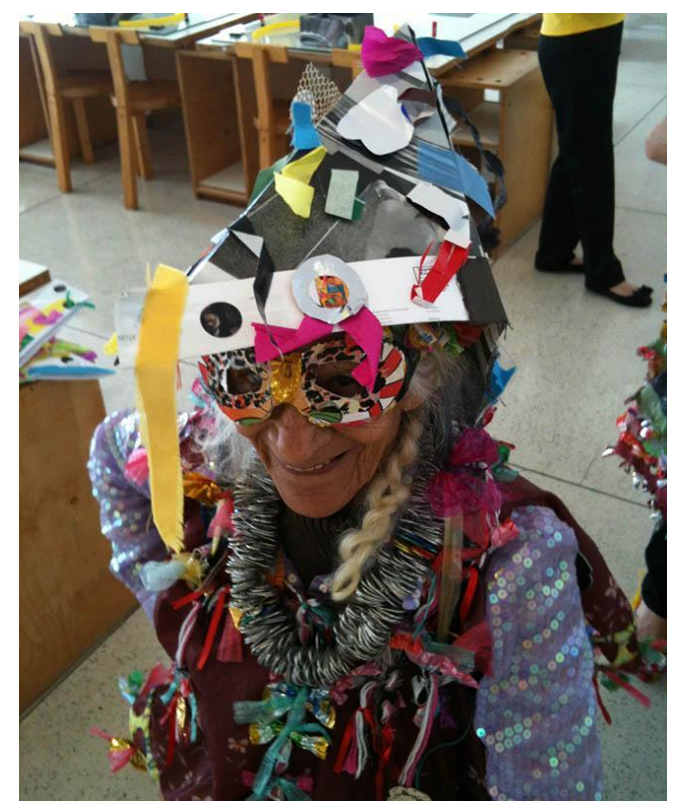

Figura 5: Efigênia Rolim posando com o chapéu da atividade prática inspirada em seus trabalhos. Fonte: Acervo de André Malinski.

Sobre a participação da Efigênia no Museu Oscar Niemeyer, Karine Serafim, coordenadora da Oficina da Ação Educativa, afirma:

Cada "Domingo + Arte" é muito característico e especial, cada artista tem sua particularidade e no caso de Efigênia Rolim não poderia ser diferente. Esta querida senhora encantou a todos com seu jeito simples e alegre de ser. A todo o momento estava disposta, contando histórias, dançando, cantando e até fazendo cambalhotas! Sua participação foi extremamente importante para o êxito das oficinas, apesar de não deixar bem claro o que deveria ser feito pelos participantes, sua felicidade e empolgação contagiou a todos que estavam ali, estimulando-os para irem além. As duas temáticas e técnicas utilizadas obtiveram um grande sucesso nos dois domingos, com sessões lotadas. Mas percebi que o apito foi sensacional, as pessoas saíam muito 
realizadas e as crianças então, nem se fala. Era o som do apito por todo o museu. A oficina dos anjinhos de sacola nos impressionou bastante, não estávamos muito confiantes em aplicá-la, pois parecia que o resultado não ficaria tão bom, que as pessoas sairiam frustradas. Para nossa surpresa aconteceu exatamente o contrário, elas adoraram. "Quem diria, fazer anjos de sacola de mercado", frases como esta eram ouvidas constantemente [...]. As oficinas deram tão certo que implementamos o apito em nossas atividades diárias com os agendamentos da Ação Educativa. (SERAFIM, 2014 ${ }^{14}$ )

O relato de Karine confirma não apenas a eficiência do trabalho artístico de Efigênia Rolim como tema para arte educação, mas principalmente a boa receptividade da artista junto ao público. No período em que suas obras estiveram expostas, Efigênia ganhou espaço e notoriedade dentro do museu, especialmente entre os funcionários de outros departamentos, que inclusive colaboravam ativamente com a coleta de materiais para as oficinas. Durante a Bienal, Efigênia foi o tipo de artista que não ficava restrita ao seu espaço expositivo, mas que comovia cada pessoa que passava pelo museu - mesmo quando ausente - e talvez ressignificando não apenas o lixo, mas os próprios visitantes.

\section{Considerações finais}

Em nossa abordagem sobre a relação dos participantes da oficina do setor educativo do MON com o lixo, buscamos a reflexão dos visitantes do museu com relação ao mundo em que vivem, mas também

${ }^{14}$ SERAFIM, Karine. Depoimento concedido aos autores, em Curitiba, 05/09/2014. 
sobre como se comportam diante deste viver na coletividade urbana. Lembrar o humilde e nobre gesto de Efigênia ao se curvar para apanhar o brilhante papel de bala - que não era uma esmeralda - faz pensar em como é essencial para a nossa sociedade vazia se curvar e reverenciar o ínfimo; "é preciso transver o mundo", concluiu o poeta Manoel de Barros. Se o olhar do artista é transformador e faz dos objetos desprezados o seu maior tesouro, com isso fica a pergunta: quem terá coragem de seguir o gesto de Efigênia?

O potencial educativo a partir do trabalho de Efigênia é suficientemente forte para transformar profundamente os que se propõem mergulhar nas possíveis reflexões que estão além da superfície das simples questões ecológicas a que o uso do lixo remete. E talvez a melhor forma de se fazer essa abordagem seja através da experimentação, e não de teorias complexas e terminologias duvidosas. Assim, suas obras inspiram ações educativas, já que esse caráter aberto e múltiplo de sua obra possibilita uma melhor apreensão dos temas que elas discutem. Isso foi percebido através do resultado bem sucedido durante as propostas aplicadas na Ação Educativa do MON em 2013.

Dizer que Efigênia Rolim dá vida ao lixo está longe de ser suficiente para definir seu trabalho artístico. Sua obra tampouco se limita a ser ecológica ou performática. Muito mais do que isto, ela recheia com sentimentos e histórias o papel de bala vazio que encontra jogado no chão. De fato, Efigênia consegue oferecer dignidade e nobreza ao que ninguém quer: o lixo. Ela questiona os valores da sociedade de consumo, superficial e descartável e os preenche com novas sensações, reflexões e 
valores. Ela transcende os rótulos e as linguagens artísticas, conquista o status de Arte dentro do espaço legitimador do museu, e ainda permanece popular. A linguagem popular de que se utiliza Efigênia não a limita à dualidade entre cultura popular e erudita: ela une as duas faces, e isso possibilita atingir às pessoas, emocioná-las e transformá-las. Ela ressignifica o lixo com seu olhar ingênuo de uma menina de 84 anos que não deixa que a imaginação se apague e que vê delicada beleza poética em tudo o que encontra disponível à sua frente: continua conseguindo ver um pássaro em uma garrafa de amaciante, uma esmeralda em um papel de bala, um tesouro em um cesto de lixo. Através de sua leveza e da simplicidade do toque de dar vida ao lixo, Efigênia Rolim nos convida para um olhar sensível e sutil sobre nossa relação com o mundo, com as palavras e com as coisas. Sua obra é capaz de nos fazer enxergar o invisível e mágico brilho de objetos que, antes dela, não julgaríamos ter valor algum. As esmeraldas, jogadas aos nossos pés, continuariam parecendo papéis de bala.

\section{Referências}

ALICE, Tania. Diluição das fronteiras entre linguagens artísticas: a performance como (r)evolução dos afetos. In: Palco Giratório: Circuito Nacional 2014. Rio de Janeiro: Sesc, 2014.

AMADO, Janaína. O grande mentiroso: Tradição, veracidade e imaginação em História Oral. História. São Paulo, 14, 1995, p.125-136.

BARROS, Manoel de. Poesia completa. São Paulo: LeYa, 2013. 
BENJAMIN, Walter. O narrador: Considerações sobre a obra de Nikolai Leskov. In: Magia e técnica, arte e política: Ensaios sobre literatura e história da cultura. São Paulo: Brasiliense, 1994.

BIENAL Internacional de Curitiba. Últimos dias para visitas as exposições da Bienal. 25 nov. 2013. Disponível em: < http://www.bienaldecuritiba.com.br/blog/ultimos-dias-para-visitar-asexposicoes-da-bienal/> Acesso em: 01 set. 2014 às 20h.

BOURDIEU, Pierre; DARBEL, Alain. O amor pela arte: os museus de arte na Europa e seu público. São Paulo: Zouk, 2003.

CANAL Futura. Conheça Efigênia, a rainha do papel. Disponível em: <http://www.youtube.com/watch? $\mathrm{v}=\mathrm{vnhhWKEFDXU \& app=desktop}>$. Acesso em: 16/11/2014.

DANTAS, Marta; BELMAIA, Nathany Wagenheimer. Efigênia Rolim: A Narradora Trapeira. In: Boitatá - Revista do GT de Literatura Oral e Popular da ANPOLL, 2011.

KASPER, Katia Maria. Eco-lógica: Efigênia entre arte e vida. Ciên. Educ., v.20 n.2, 2014, p. 331-344.

MCLUHAN, Marshall. A palavra falada. in: Os meios de comunicação como extensões do homem. São Paulo: Cultrix, 2000.

PINHEIRO, Dinah Ribas. A viagem de Efigênia Rolim nas asas do peixe voador. Curitiba: Ed. do Autor, 2012.

POLLAK, Michael. Memória e identidade social. Estudos Históricos, Rio de Janeiro, vol. 5, n. 10, 1992, p. 200-212.

SALDANHA, Nuno. Arte Popular, Arte Erudita e Multiculturalidade: Influências, confluências e transculturalidade na arte portuguesa. Lisboa: CEPCEP/ACIDI, 2008. 
SANTAELLA, Lucia. Semiótica Aplicada. São Paulo: Thomson Pioneira, 2002.

SECRETARIA da Educação do Paraná. Dia a Dia Educação. Hélio Leites. em: $<$ http://www.arte.seed.pr.gov.br/modules/conteudo/conteudo.php?conte $\mathrm{udo}=265>$. Acesso em: 16/11/2014.

SHON, Donald. Formar professores como profissionais reflexivos. In: NÓVOA, Antonio. (Org.). Os professores e a sua formação. $2^{\circ}$ ed. Lisboa: Dom Quixote, 1997. P.77-114.

WALDECK, Guacira. Armadilhas para Efigênia Rolim e Hélio Leites. In: Textos escolhidos de cultura e arte populares. Rio de Janeiro, v. 4, n. 1, 2007. P. 7-20 